\title{
Leukoencephalopathy with Brain Stem and Spinal Cord Involvement and Normal Lactate: Case Report
}

\section{Beyin Sapı ve Medulla Spinalis Tutulumu ve Normal Laktat ile Seyreden Lökoensefalopati: Olgu Sunumu}

\author{
Edis Çolak, Cenk Eraslan \\ Ege University Faculty of Medicine, Department of Radiology, Izmir, Turkey
}

\begin{abstract}
Leukoencephalopathy with brain stem and spinal cord involvement and high lactate (LBSL) include cerebral white matter, brain stem and spinal cord tract involvement on magnetic resonance imaging. Increased lactate levels on magnetic resonance spectroscopy (MRS) has been reported. In this case report, we describe a patient with LBSL and normal lactate levels on MRS.

Keywords: Brainstem, lactate, leukoencephalopathy, spinal cord
\end{abstract}

ÖZ

Manyetik rezonans görütülemede serebral beyaz madde, beyin sapı ve medulla spinalis traktuslarının tutulumu, beyin sapı ve medulla spinalis tutulumu ve laktat yüksekliği ile seyreden lökoensefalopati (LBSL) için tanı koydurucudur. Manyetik rezonans spektroskopide laktat piki bildirilmiş olsa da bu olgu sunumunda normal laktat seviyeleri gösteren LBSL özellikleri tartı̧̧ılmışıır.

Anahtar Kelimeler: Beyin sapı, laktat, lökoensefalopati, medulla spinalis

\section{Introduction}

Leukoencephalopathy with brain stem and spinal cord involvement and lactate elevation (LBSL) is a rare, autosomal recessive disorder (1-3). Signal abnormalities in the cerebral white matter, medulla oblongata, lateral corticospinal tracts and dorsal columns of the spinal cord are the major diagnostic criteria of LBSL (4). Signal abnormalities in the cerebellar white matter, superior and inferior cerebellar peduncles, trigeminal tracts, splenium of the corpus callosum and posterior limb of the internal capsule are the supportive criteria of LBSL (4). On magnetic resonance spectroscopy (MRS) of the abnormal white matter there are usually increased lactate levels. (4). In this case report, we describe a patient with LBSL and normal lactate levels on MRS.

\section{Case Report}

A 15-year-old female patient had a seven years history of weakness in legs, postural instability and slurred speech. The symptoms were slowly progressive. There was no consanguinity in the family. Her medical history revealed that she had a loss of consciousness and vomiting at the age of six years after trauma.

Neurological examination at age 15 revealed a prominent weakness of the legs and increased tendon reflexes. Bilateral lower extremity muscle strength was reduced. Laboratory studies including complete blood count, glucose, cholesterol levels, vitamins, electrolytes and metabolic diseases tests were all normal.

The cranial magnetic resonance imaging (MRI) showed multifocal signal abnormalities as hyperintens on T2-weighted 
images and hypointense on T1- weighted images in the cerebral white matter (Figure 1), in the pyramids of medulla oblongata (Figure 2), in the dorsal columns and the lateral corticospinal tracts of cervical and thoracic part of the spinal cord (Figure 3).

There were also signal abnormalities in the splenium of the corpus callosum, posterior limb of the internal capsule (Figure 4), superior and inferior cerebellar peduncles (Figure 5) and cerebellar white matter (Figure 6). None of the lesions showed enhancement after gadolinium administration. The multivoxel MRS of the cerebral white matter lesions revealed decreased $\mathrm{N}$-acetylaspartate, increased choline and normal lactate levels (Figure 7).

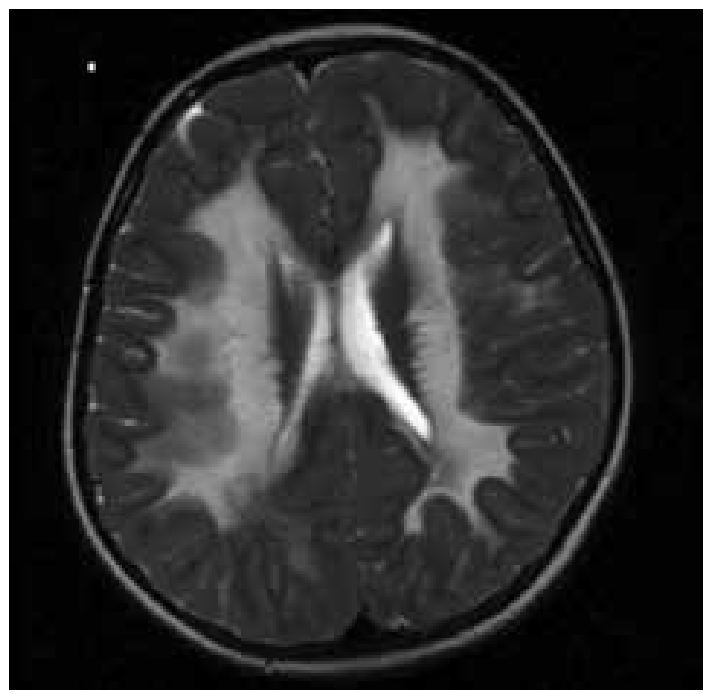

Figure 1. Axial T2-weighted cranial magnetic resonance imaging showing multifocal confluent hyperintense signal abnormalities in the periventricular cerebral white matter

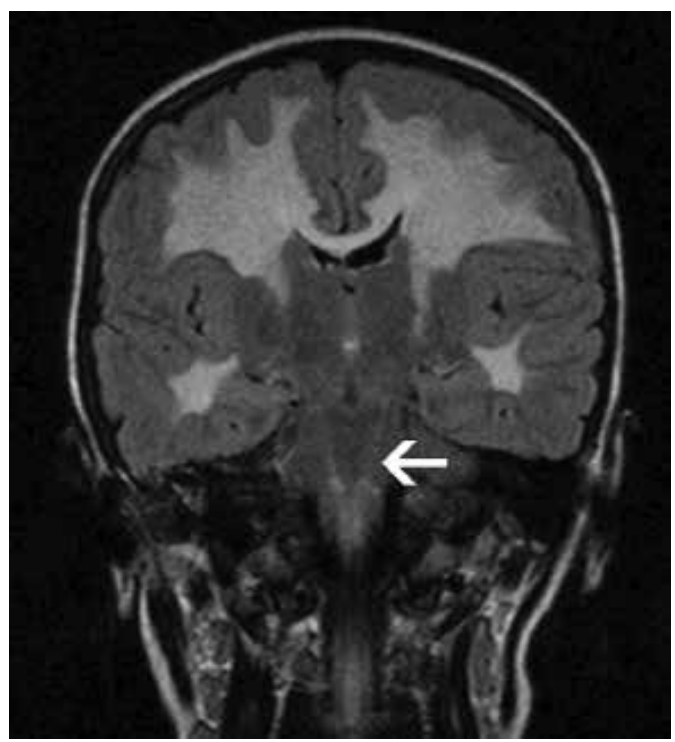

Figure 2. Axial T2-weighted cranial magnetic resonance imaging showing hyperintense signal abnormalities in the pyramids (white arrow)

\section{Discussion}

LBSL is a rare, autosomal recessive disorder. Mutations in the DARS2 gene are associated with LBSL (1-3). Molecular genetic tests were not performed on the patient described in this article.

Signal abnormalities in the cerebral white matter, pyramids of the medulla oblongata, lateral corticospinal tracts and dorsal columns of the spinal cord are the major brain and spinal cord MRI diagnostic criteria of LBSL. For an MRI-based diagnosis, all major criteria should be completed (4-6). The cranial MRI of our patient showed presence of all the three major criteria which include multifocal, confluent abnormalities in the cerebral white matter, signal abnormalities in the pyramids of the medulla oblongata, and signal abnormalities in the dorsal columns and the lateral corticospinal tracts of cervical and thoracic part of the spinal cord.

Signal abnormalities in the cerebellar white matter, superior and inferior cerebellar peduncles, trigeminal tracts, splenium of the corpus callosum and posterior limb of the internal capsule are the supportive criteria of LBSL. For an MRI-based diagnosis, all major criteria and at least one supportive criterion should be completed (4-6). Cranial MRI of our case showed presence of five supportive criteria which include signal abnormalities in the splenium of the corpus callosum, posterior limb of the internal capsule,

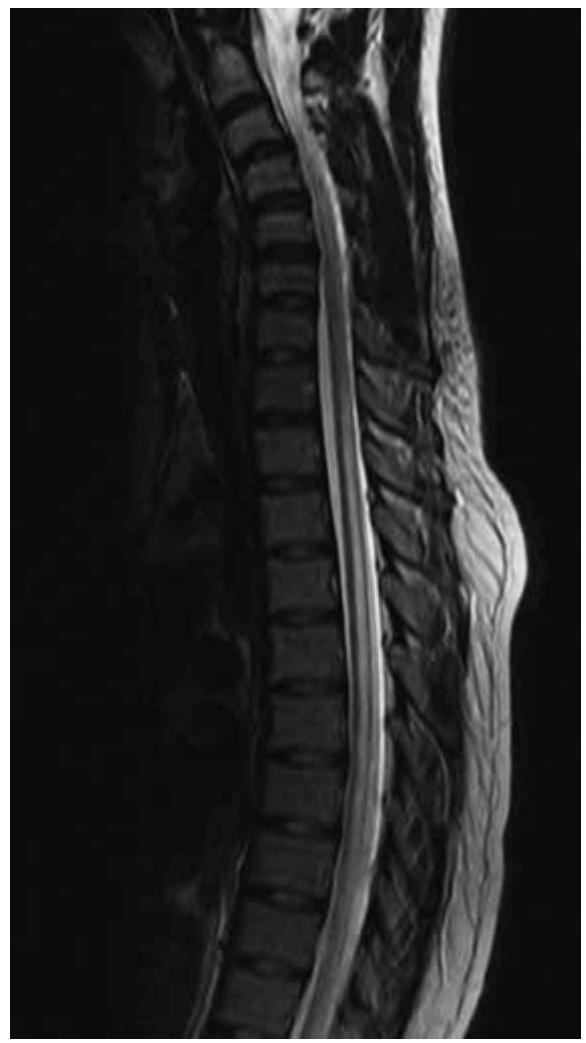

Figure 3. Sagittal T2-weighted spinal cord magnetic resonance imaging showing hyperintense signal abnormalities in the spinal cord 
superior and inferior cerebellar peduncles and cerebellar white matter.

Lesions refers low signal on T1-weighted images and high signal on T2-weighted images (4-6). The patient described in this paper had the diagnostic MRI pattern of the disease.

On MRS of the abnormal white matter there are usually increased lactate levels. For an LBSL diagnosis, all major $\mathrm{MRI}$ criteria and at least one supportive criterion should be completed whether lactate is elevated or not (7-9). MRS findings, including decreased $\mathrm{N}$-acetylaspartate and increased choline due to axonal degeneration (10). Our patient's multivoxel MRS of the cerebral white matter lesions

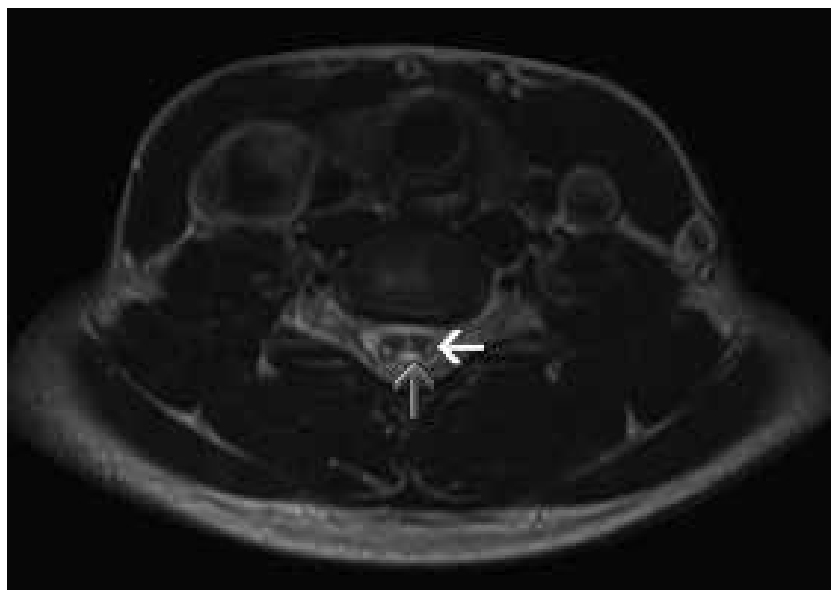

Figure 4. Axial T2-weighted spinal cord magnetic resonance imaging showing abnormal signal in the dorsal columns (grey arrow) and lateral corticospinal tracts (white arrow)

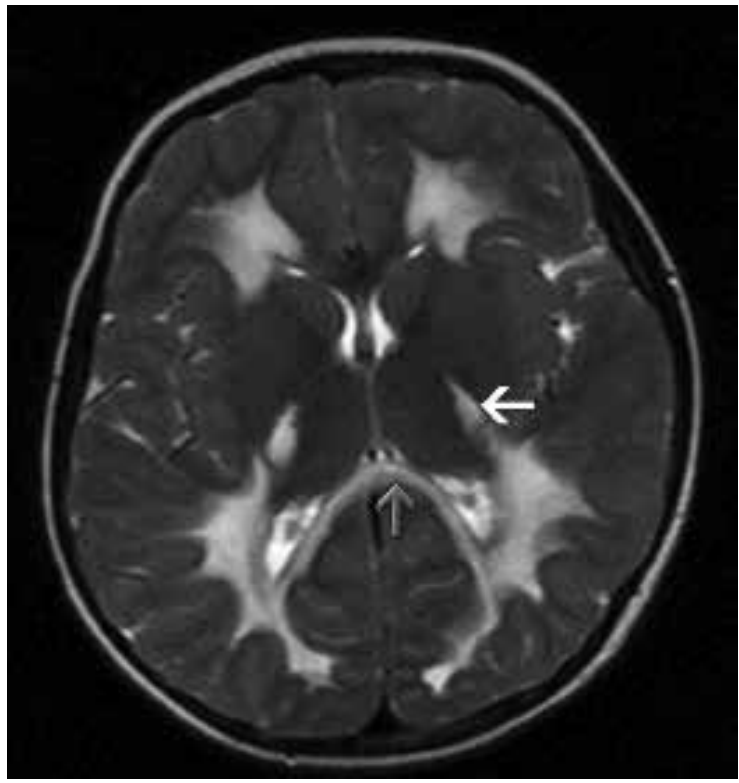

Figure 5. Axial T2-weighted cranial magnetic resonance imaging showing hyperintense signal abnormalities in the splenium of the corpus callosum (grey arrow) and posterior limb of the internal capsule (white arrow) revealed decreased $\mathrm{N}$-acetylaspartate, increased choline and normal lactate levels (Figure 8).

The disease spectrum ranges from neonatal to adult onset. Neonatal onset patients have a heavy disease course and may die, while adult onset disease is slowly progressive involving dysarthria, ataxia, spasticity, and epilepsy $(11,12)$. Our patient is a 15-year-old female. She had a seven-year history of weakness in legs, postural instability and slurred speech. The symptoms had progressed slowly. Neurological

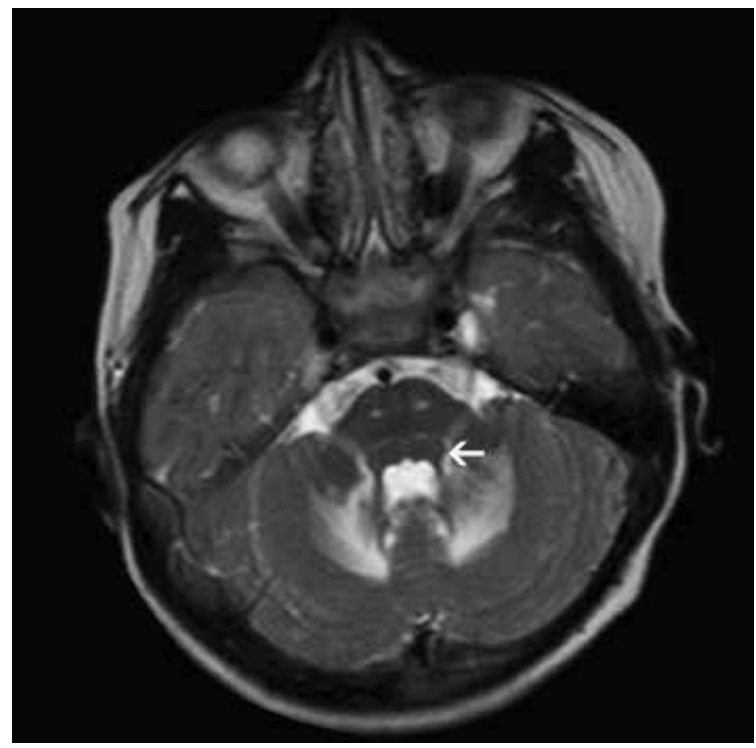

Figure 6. Axial T2-weighted cranial magnetic resonance imaging showing hyperintense signal abnormalities in the superior cerebellar peduncles (white arrow)

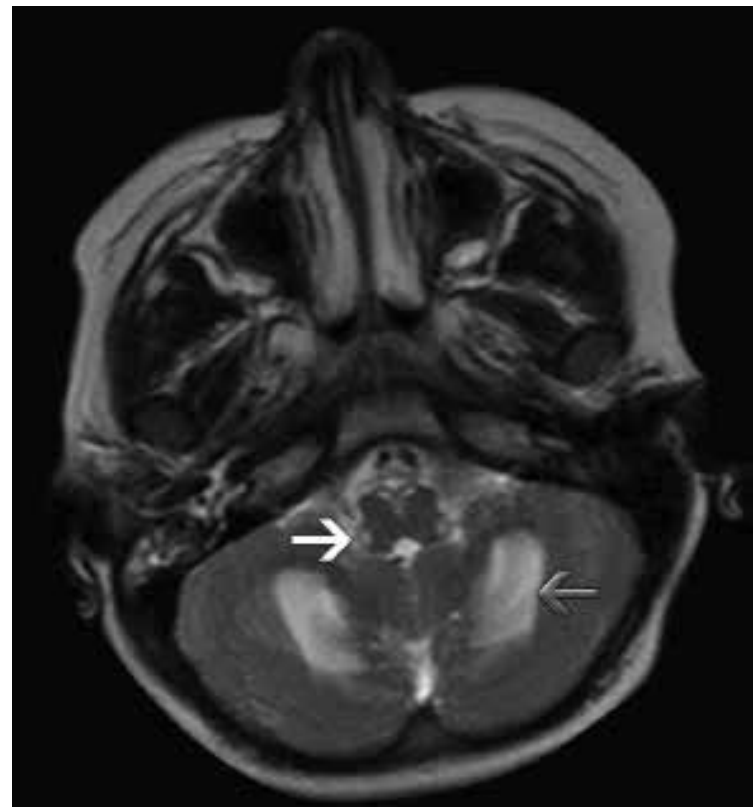

Figure 7. Axial T2-weighted cranial magnetic resonance imaging showing hyperintense signal abnormalities in the inferior cerebellar peduncles (white arrow) and cerebellar white matter (grey arrow) 


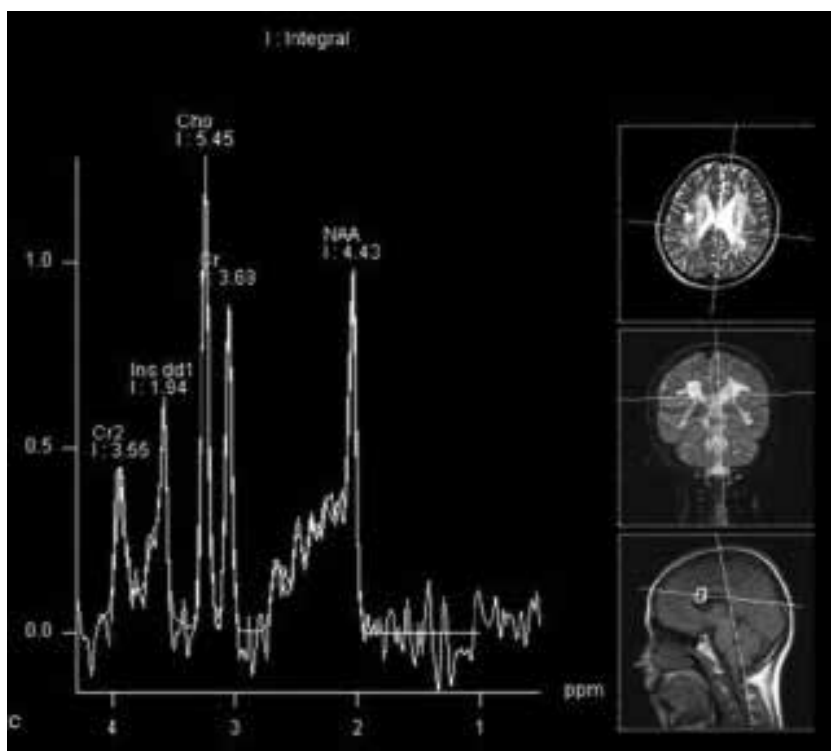

Figure 8. Magnetic resonance spectroscopy of the cerebellar white matter shows increased choline and creatine and decreased $\mathrm{N}$-acetylaspartate levels. There was no evidence of lactate elevation

examination at age 15 revealed a prominent weakness of the legs and increased tendon reflexes. Bilateral lower extremity muscle strength was reduced.

All major and five supportive MRI diagnostic criteria of LBSL in our patient were fulfilled, but MRS showed normal lactate levels in the affected cerebral white matter. A few radiological LBSL cases with genetic confirmation have been reported before with normal lactate levels $(7,13,14)$. The reason of normal lactate levels is not yet known.

With this case report, we wish to underline that the LBSL with a distinct clinical and radiological presentation may have normal lactate levels in the affected cerebral white matter.

\section{Ethics}

Informed Consent: It was taken.

Peer-review: Externally and Internally peer-reviewed.

\section{Authorship Contributions}

Surgical and Medical Practices: Edis Çolak, Cenk Eraslan, Concept: Edis Çolak, Cenk Eraslan, Design: Edis Çolak, Cenk Eraslan, Data Collection or Processing: Edis Çolak, Cenk Eraslan, Analysis or Interpretation: Edis Çolak, Cenk Eraslan, Literature Search: Edis Çolak, Writing: Edis Çolak.

Conflict of Interest: No conflict of interest was declared by the authors.

Financial Disclosure: The authors declared that this study received no financial support.

\section{References}

1. Scheper GC, van der Klok T, van Andel RJ, et al. Mitochondrial aspartyl-tRNA synthetase deficiency causes leukoencephalopathy with brain stem and spinal cord involvement and lactate elevation. Nat Genet 2007;39:5349.

2. Bonnefond L, Fender A, Rudinger-Thirion J, Giege R, Florentz C, Sissler M. Toward the full set of human mitochondrial aminoacyl-tRNA synthetases: characterization of AspRS and TyrRS. Biochemistry 2005;44:4805-16.

3. Delarue M, Poterszman A, Nikonov S, Garber M, Moras D, Thierry JC. Crystal structure of a prokaryotic aspartyl tRNAsynthetase. EMBO J 1994;13:3219-29.

4. van der Knaap MS, van der Voorn P, Barkhof $F$, et al. A new leukoencephalopathy with brainstem and spinal cord involvement and high lactate. Ann Neurol 2003;53:252-8.

5. Scheper GC, van der Klok T, van Andel RJ, et al. Mitochondrial aspartyl-tRNA synthetase deficiency causes leukoencephalopathy with brain stem and spinal cord involvement and lactate elevation. Nat Genet 2007;39:5349.

6. Steenweg ME, van Berge L, van Berkel CG, et al. Earlyonset LBSL: how severe does it get? Neuropediatrics 2012;43:332-8.

7. Petzold GC, Bohner G, Klingebiel R, Amberger $N$, van der Knaap MS, Zschenderlein R. Adult onset leucoencephalopathy with brain stem and spinal cord involvement and normal lactate. J Neurol Neurosurg Psychiatry 2006;77:889-91.

8. Labauge $\mathrm{P}$, Roullet E, Boespflug-Tanguy $\mathrm{O}$, et al. Familial, adult onset form of leukoencephalopathy with brain stem and spinal cord involvement: inconstant high brain lactate and very slow disease progression. Eur Neurol 2007;58:5961.

9. Tavora DG, Nakayama M, Gama RL, Alvim TC, Portugal D, Comerlato EA. Leukoencephalopathy with brainstem and spinal cord involvement and high brain lactate: report of three Brazilian patients. Arq Neuropsiquiatr 2007;65:506-11.

10. Linnankivi $T$, Lundbom $N$, Autti $T$, et al. Five new cases of a recently described leukoencephalopathy with high brain lactate. Neurology 2004;63:688-92.

11. van Berge $L$, Hamilton EM, Linnankivi $T$, et al. Leukoencephalopathy with brainstem and spinal cord involvement and lactate elevation: clinical and genetic characterization and target for therapy. Brain 2014;137:101929.

12. Akçay AA, Keskin S, Gökben S. A case of slowly porgressive encephalopahty. Annual meeting of European Academy of Childhood Disability and Joint of National Pediatric Neurology Congress. Istanbul: Poster presentations 2012.

13. Serkov SV, Pronin IN, Bykova OV, et al. Five patients with a recently described novel leukoencephalopathy with brainstem and spinal cord involvement and elevated lactate. Neuropediatrics 2004;35:1-5.

14. Uluc K, Baskan O, Yildirim KA, et al. Leukoencephalopathy with brain stem and spinal cord involvement and high lactate: a genetically proven case with distinct MRI findings. J Neurol Sci 2008;273:118-22. 